Acta Universitatis Wratislaviensis No 3920

Anglica Wratislaviensia LVII, Wrocław 2019

DOI: 10.19195/0301-7966.57.12

\author{
Paweł Stańko \\ ORCID: 0000-0001-5535-7873 \\ Philological School of Higher Education, Wroclaw \\ pawel_stanko@wp.pl
}

\title{
Cowboy and Samurai Values and Their Exponents in the Western A Fistful of Dollars (1964) and Its Predecessor the Samurai Movie Yojimbo (1961): Proposal of a Methodological Framework for Axiological Analyses of Multimodal Filmic Texts
}

\begin{abstract}
This paper focuses on the issue of valuations and values in the chosen movies linked by the relationship of remaking. Its goal is to show that the complexity of multimodal texts, to which filmic texts and therefore remakes belong, makes it necessary to examine the axiological level of film texts too. In this way we hope to prove that the amply justified and evidenced axiological aspects of language (cf. Krzeszowski, Angels, Aspekty, Equivalence; Puzynina, "Językoznawstwo", Język) are also a property of primarily visual film texts. Consequently, the very aspects of the relationship of remaking itself that the two films share, i.e. the fact that the film A Fistful of Dollars (1964) is a remake of Yojimbo (1961), is not examined in this paper. Instead, we restricted our attempt to showing how axiological charges and values are expressed in the process of remaking. The basis of the analysis is the compositional level and the compositional-narrative structure of filmic texts, a choice which correlates with the approach to multimodality of filmic texts described in Post (Film). The sample axiological analysis presented in the fourth section of this paper relies on the approaches of Krzeszowski (Angels, Meaning), Puzynina ("Językoznawstwo", Język) and Post (Film). With the instruments selected from these works we underline the differences and similarities between values and axiological charges present in both films as well as their importance and impact on the overall meaning of filmic segments.
\end{abstract}

Keywords: discourse analysis, text analysis, multimodal linguistics, axiological semantics, value, axiological charge, domain of values 


\section{Introduction}

The present paper deals with the issue of axiological elements in filmic texts, the illustrations being derived from two films connected by the relationship of remaking. Specifically, this paper focuses on two types of axiological elements in filmic texts, namely (i) values and (ii) their visual exponents. If a semantic analysis is not to be incomplete (see Krzeszowski, Angels), it is necessary for it to include these axiological elements. The selected films are multimodal and the goal of multimodal analysis of these films is to explain how a message/meaning containing axiological elements is made by the interaction of their modes (Post, Film 147-165).

There are three observations relevant for the analysis and discussion in this paper that the selected movies justify. The first is that values are largely based on one's culture and thus may not be shared. Although the movies belong to "Cowboy" and "Samurai" cultures, respectively, they do share values that are expressed differently and take various forms to satisfy the requirements of their cultures, as shown below by the selected films. Secondly, values are not directly stated but rather determined (recovered) on the basis of various situations and characters' actions in the movies - in the ways characteristic of cultures, among others. The third observation is that in a filmic text, values are implicitly present within all of its three modalities - visual modality, auditory modality and linguistic modality. In other words, the three filmic modalities are the exponents of these values.

The illustration and support for the above observations come from the author's analysis of the selected parts of the Western remake A Fistful of Dollars (1964) by Sergio Leone of Akira Kurosawa's Samurai movie Yojimbo (1961). ${ }^{1}$ There are three reasons for which films connected by the relationship of remaking have been chosen for their juxtaposition. The first of them is the ground of comparisontertium comparationis linking both movies. We mean the similar plots (thematic structure) that they share due to the fact one of them is a remake of the source film, both belonging to the same movie genre western, more precisely, to spaghetti and samurai westerns, respectively. The second reason is the parallel compositional-narrative structures composed of segments of variable size, which are the elements suitable for a comparison. The third reason is that both analyzed films, being multimodal objects, involve the three filmic modalities - visual modality, auditory modality and linguistic modality, which create meaning of each movie segment. However, this last property is not obligatory as evidenced by the existence of film adaptation and film novelization.

The paper has the following structure. The present section is followed by Section 2 which enumerates the major aspects of the research perspective. Section 3 presents the proposed interpretative framework for axiological analyses of filmic texts. The two sections lead to the exemplary analysis in Section 4, which includes selected

1 The present paper is part of the author's larger-scale research project that concerns the presence, role and importance of axiology in cross-cultural multimodal translation of movies. 
fragments from the chosen filmic texts connected by the relationship of remakingA Fistful of Dollars (1964) by Sergio Leone and Yojimbo (1961) by Akira Kurosawa.

\section{Major aspects of the research perspective}

For the purpose of multimodal axiological analysis, we view films as texts because of the general structure they share with linguistic text - (1) the five-level generalized text pattern (Post, Film 22; Ostaszewska and Cudak). The five levels of this pattern are the pragmatic level, thematic level, compositional level, stylistic level and axiological level. Values belong to the axiological level of text pattern in the aforementioned five-level generalized text pattern (Post, Speech). The three filmic modalities - linguistic modality, visual modality and auditory modality belong to the stylistic level of the generalized text pattern. They are (i) bearers of values and (ii) exponents of axiological charges, which constitute part of the meaning of each movie segment of the compositional-narrative structure of film texts, and thus the meaning of the whole filmic text. Axiological charges refer to the positive or negative nature of modalities and values. Because values are implied, it is worth noting that the three modalities may have different content and still represent the same values and charges, as is shown by the example of the analyzed movies.

The adopted axiological framework involves relevant elements of axiological pragmatics (Puzynina, "Językoznawstwo", Język), axiological semantics (Krzeszowski, Angels, Aspekty, Meaning) and axiological linguistics (Post, Speech). For the present axiological analysis of the chosen filmic segments, the following instruments have been adopted. The typology of values based on Puzynina's hierarchy of values ("Językoznawstwo", Język) and Krzeszowski's axiologized preconceptual image schemata as well as his Fundamental Axiological Matrix (FAMA) (Angels, Meaning), which enables one to distinguish the "absolute value" (Krzeszowski, Angels 132), i.e. a final axiological charge, in a relationship of two or more values that might have different axiological charges. Both have been altered for the purposes of the multimodal and axiological analysis. In Section 3.3 below we discuss in some detail the above two aspects of our research perspective.

\section{Interpretative framework for axiological analyses of film texts}

3.1. Segments of compositional-narrative structure of filmic text as units of axiological analyses

Like literary texts, the filmic text is defined by the same generalized text pattern. As indicated above, this pattern is a five-level structure comprising pragmatic level, thematic level, compositional level, stylistic level and axiological level. However, 
it does not have a fixed and invariable internal structure, with each of its levels being capable of having a higher degree of importance in relation to the other levels, and the ability to interact with them accordingly (Post, Film 22). In our analysis the compositional level is central. The compositional-narrative structure of the filmic text consists of three major parts - the two parts of metaframe and the text proper (Post, Film 93-94). These three segments form the highest level of the compositional-narrative structure hierarchy-level 1 . The function of metaframes is to delimitate the boundaries of text proper, as both introduce and end its content. The metaframes have been excluded from the present analysis as the relevant Cowboy and Samurai values and their axiological charges are mainly present in the text proper of the compositional-narrative structure.

The major element of the compositional-narrative structure, that is, text proper, serves the same function in filmic and literary texts - telling a story. The structure of text proper refers to Aristotle's three-act paradigm and is further divided into smaller segments, which make the compositional-narrative structure more complex and detailed (see Gulino; Freytag; Post, Film), ${ }^{2}$ allowing for a more in-depth analysis of its content. Of the numerous available proposals, we adopted the one specified by Krajka and Zgorzelski as seven segments, each based on the events taking place in the plot. These segments constitute the second level (level 2) of the compositional-narrative structure and appear in the text proper in the following order: PROLOGUE, EXPOSITION, INCITING MOMENT, THE DEVELOPMENT OF ACTION, THE CLIMAX, DENOUEMENT and EPILOGUE.

In order to achieve a more accurate and detailed analysis, the third level of compositional-structure was further delimited. For this purpose, the model of text analysis devised by Swales was implemented, which operates with two types of compositional segments called MOVES and Steps. In case of filmic texts, MOVES are long scenes, not individual shots, used as means of telling the film's story. They are subdivided into Steps, which, in filmic texts, often take the form of short scenes or shots. Swales' theory is necessary as it enables us to define precisely the lowest units of the compositional-narrative structure essential to the analysis.

In conclusion, each of the compositional-narrative segments of the text proper, consists of MOVES, which jointly create the third level of compositional hierarchy (level 3). Each of these MOVES is in turn made of Steps, which comprise the fourth level of the hierarchy (level 4). These segments of the compositional-narrative structure are comprised of modalities, which are the exponents of values.

2 Gustav Freytag and Paul Gulino are the authors relevant to this paper. Freytag's proposition is the so-called "Freytag's Pyramid" illustrating the narrative structure of dramatic works in general (see Freytag), whereas Gulino focuses on the compositional structure of films with "the Sequence Approach" (see Gulino). 
3.2. Multimodality of film texts and the formation of filmic meaning

Recently, several theories regarding movies as multimodal texts have been offered by Burn, Barsam, Bateman (Analysis, Introduction), Wildfeuer (Interpretation), Wildfeuer and Bateman (Analysis) and Post (Film). The approaches to multimodal analysis of filmic texts of Wildfeuer (Interpretation) and by Wildfeuer and Bateman (Analysis) differ from the approach followed in this paper. They propose new paradigms involving unique instruments of filmic text analysis different from the existing ones to a maximum degree. As underlined before, the approach in this paper, presenting a novel model of multimodal analysis, uses a broad range of elements present in the analysis of literary text, thus underlining the similarities between filmic and literary texts (cf. Post, Film).

Stories told by the multimodal filmic text are located within its compositional-narrative structure (compositional level). As indicated above, compositional structure is made of smaller segments. Each segment carries a portion of the story of the movie. Part of these messages is their axiological charge. The form of each compositional segment is made up of three filmic modalities, that is, linguistic modality, visual modality and auditory modality. They serve as elements jointly carrying the meaning of each movie segment together endowed with axiological charge. The place of axiological elements in the overall meaning of filmic segments is schematically presented by figure 1 , which is an expanded version of de Saussure's model of linguistic sign (Post, Film 150).

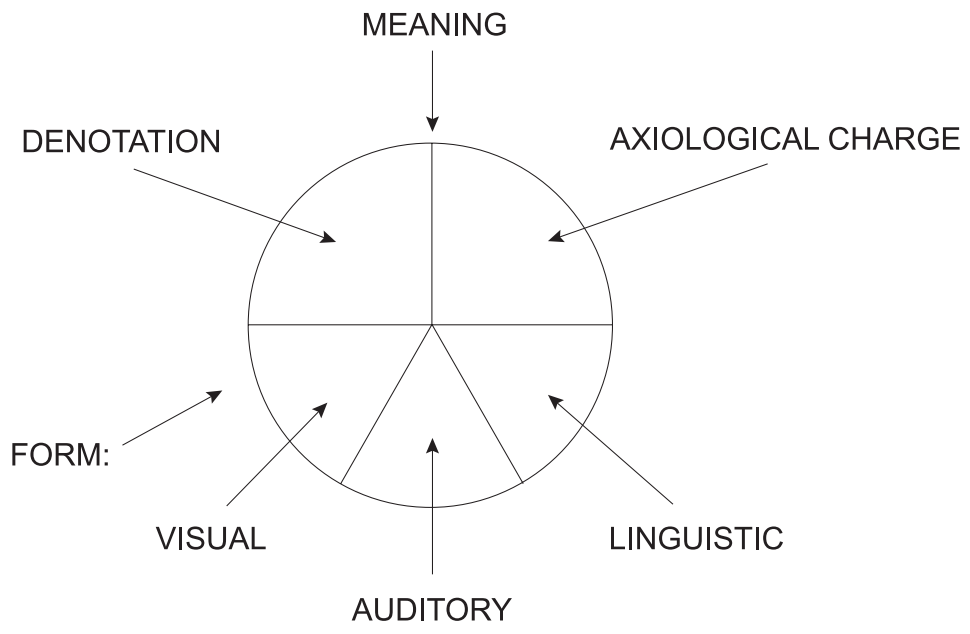

Figure 1: Filmic sign—multimodal sign

Source: Post, Film 150.

As regards the construal of meaning, it relies on the parts of each modality present in the chosen movie segment - in our research these "parts" have been called multimodal message chunks (Post, Film 140). Such chunks are the units 
subjected to the analysis. By adding linguistic, visual and auditory chunks together it is possible to elaborate the overall message of each movie segment. To generalize, the overall message of the segments on the lower level of the compositional narrative structure (Steps) constitutes the overall message of the segments on the higher level (MOVES). Similarly, MOVES constitute the overall meaning of the higher level segment, e.g. PROLOGUE and EXPOSITION.

When talking about the construction of meaning of each movie segment, it is appropriate to underline the ways the axiological elements and values (denotations) are manifested. As indicated earlier, these values are not stated directly but rather implied by the three modalities (form), which are also the exponents of the axiological charge, which is either positive or negative relative to a certain level of values. Denotation and axiological charge constitute the meaning and indicate the position of values on the positive-negative axis. For example, when considering a person skilled in firearms living in the Wild West, a Cowboy may be considered as representing the positive $(+)$ pole of the axis whereas a bandit may be considered as representing the negative (-) one. Another example may be a surgeon on the positive side of the axis and a witch doctor on the negative side of it.

\subsection{Axiological semantics for multimodal film texts}

As indicated at the outset, the necessary extension of the scope of analyses of multimodal texts is possible by considering axiological elements and their impact on the overall meaning. The system of values we followed in the conducted research is based on Puzynina's ("Językoznawstwo", Język) views on this topic. To describe these values we apply the concept of the Domain of Values (Krzeszowski, Angels 64-75). The Domain of Values consists of a vertical up-down axis and horizontal left-right axes. The vertical axis arranges different types of values into a hierarchy in which values on the top of the up-down axis are situated higher in the hierarchy, from less important (down) to most important (up). ${ }^{3}$ The horizontal left-right axes, on the other hand, are the PLUS-MINUS scales located at the level of each value and represent two coordinates with respect to which axiological charges of concepts are estimated. These axes, that is, the vertical and horizontal axes, refer to the positive and negative character of values and their place in the hierarchy of values, respectively.

Other instruments of axiological analysis come from Krzeszowski's (Angels, Aspekty, Meaning) model of Axiological Semantics, which is an extension of Langacker's Cognitive Grammar. These involve the concepts of Preconceptual

${ }^{3}$ Krzeszowski's (Angels 64-75) hierarchy of values stems from the Great Chain of Being with its elements correlating with different value types: God - transcendental values, humans - spiritual values, animals - emotional values, plants - vital values and inorganic things - sensual values. 
Image Schemata, Figure and Ground, Fundamental Axiological Matrix (FAMA), as well as Axiological Clashes, which appear as a result of a negative final axiological charge in a relationship of values. The proposed comprehensive approach to axiology of film texts, hopefully, makes it possible to examine thoroughly each movie segment and discover the values it implies as well as to estimate its axiological charges.

\section{Culture-determined Cowboy and Samurai values}

The main characters of the analyzed movies are knights errant. The protagonist of Yojimbo (1961) is a Ronin whose character was translated into a western Drifter in A Fistful of Dollars (1964), which is achieved by adapting the value system from Japanese to American culture where the mentioned figures are archetypes, often viewed as role models.

In the Western culture, the Cowboy is often associated with a hero roaming the Wild West. Moskowitz argues that the character of the Cowboy has its roots in the depictions of the medieval knight. In her work she states that the "Cowboy can be seen as the American incarnation of the knight" (Moskowitz 8). As an example she mentions the English knight and his romanticization throughout centuries, which underlined his chivalry and virtues. In his book, Owen (Values) traces the Cowboy's archetype back to the days of the American frontier, where law was not yet established. He stresses the importance of Cowboys as authority figures who, guided by the "Code of the West" - the moral system of the Cowboy —often acted as keepers of justice.

The Cowboy, much like the Samurai, has many depictions and is a known figure in history. Though not enforced and formal, unlike the Samurai's Bushido, it was the Code of the West that guided the actions of the Cowboy. As mentioned before, the Cowboy's roots are, among other things, in the character of the medieval knight (Moskowitz). As the values connecting the two archetypes, Moskowitz mentions their nobility, heroism, generosity and endurance. When mentioning the archetype of the medieval knight it is imperative to also underline the impact Christianity had on shaping his character, and how it affects the archetype of the Cowboy. Virtues such as kindness and compassion are often seen in westerns such as Shane (1953), where a stranger (drifter) decides to help a community in need. According to Owen (Values 22), the mentioned Code of the West represents values such as "honesty, loyalty and authenticity" as well as "optimism, courage, hard work and fair play." Apart from that, they "routinely smoked, drank, and cursed" (Owen, Ethics 21) and many of them were quite eager to earn money catching wanted criminals (bounty hunters) or by serving as armed escorts, as illustrated in the movies 3:10 to Yuma (2007) or For a Few Dollars More (1965). These values are reflected by the drifter Joe in A Fistful of Dollars (1964) and make it possible 
to use of the Code of the West to help construct the value system of the drifter in the context of movies pertaining to the Wild West.

As regards the values of both Samurai and Cowboy, they originate from different periods in history and from different sources. Samurai values or, as they are often called, the code of the Samurai, have their roots in some Asian religions and philosophical doctrines. One of these religions is Buddhism, where stoicism and the approach to inevitability are important aspects of Bushido - the way of the warrior (Nitobe 7). Another religious source is Shintoism and its focus on "loyalty to the sovereign" and "reverence for ancestral memory", (Nitobe 7) often observed in the way the Samurai behaves towards its lord and the elderly and how he remembers them. According to Nitobe (8), the code of the Samurai was also affected by prominent philosophers such as Confucius and his five key relationships, as well as Mencius, whose "forcible and often quite democratic theories" were becoming more and more popular at the time. Moreover, the teachings of these philosophers were made into books for both the young and the old (Nitobe 9), and therefore made a lasting impact on Japanese culture and on Bushido.

The Samurai is a widely renowned and famous figure in history. His actions and way of life were guided by Bushido, the way of the warrior, which may be considered a system of values of the Samurai. One of the most basic principles that the Samurai adheres to is the sense of right and wrong - or good and evil, which dictates how he should behave (Cleary and Ratti 18). Acting wrongly can be considered shameful, immature and cowardly - that includes dangerous situations where the Samurai is required to be courageous and act without hesitation (Cleary and Ratti 20). Another important aspect of the Samurai code was frugality - the Samurai was advised to save his money and use it only when necessary, without overspending (Cleary and Ratti 39-40).

Many Samurai values also come from the previously mentioned religion of Shintoism. As Knapp (186) points out, Shintoism is in the heart of Japanese culture and contributes immensely to the code of Samurai as "it signifies the character of higher sense - courage, courtesy, honour, and above things loyalty" as well as "the zest of duty" and "the readiness to surrender life for a principle without a thought of wherefore" (Lafcadio 388). Nitobe (9-10) argues, that "rectitude or justice" are central in Bushido, because they are the very foundation of the Samurai's actions - the Samurai does not take part in illegal activities and despises corruption. Without them, he states, the Samurai cannot be himself, no matter how talented and skilled he is.

As mentioned earlier, Bushido was influenced by the teachings of Confucius, who stressed the importance of benevolence as one of the virtues a ruler should have (Nitobe 13). Samurai were often the ruling caste and thus benevolence became a respected trait, as were "magnanimity, affection for others, sympathy and pity" (Nitobe 14). The above-mentioned traits and features of character, along with the close examination of the protagonist of Yojimbo (1961) make it possible to construct the system of values of the Samurai. 


\section{Example analysis}

The analysis has been conducted in the following three steps. Firstly, both films have been thoroughly analyzed so as to recognize the behaviour and actions of the characters - the Samurai and the Cowboy, and then the values that they imply were assigned and organized into hierarchy of values. Secondly, the frequency of occurrence of these values in the compositional-narrative structure of the films has been established, in order to examine their importance. Thirdly, analysis proper of the values has been carried out by comparing the systems of values relevant to both archetypes, with special attention paid to the values that were transferred from the original film Yojimbo (1961) to its remake A Fistful of Dollars (1964).

\subsection{Hierarchies of Cowboy and Samurai values as reflected in the selected movies}

In order to analyze the values characterizing both archetypes - the Cowboy and the Samurai - the system of values for each archetype must be established. To achieve this, the moral code and behaviour of the Cowboy and the Samurai has to be closely examined - in filmic texts it is assessed on the basis of its appearance in the movie segments. After examining the three modalities (bearers of values) constituting the filmic segments of the compositional-narrative structure, the values are recognized and assigned to a category. In this paper, these categories are based on the typology by Puzynina (Jezzyk 40) and include the following types of values: cognitive values, aesthetic values, moral values, customary values, vital values and emotional values. The aforementioned system of values is comprised of universal enough values. These systems of values have been chosen for both movies due to the relationship of remaking connecting them. The values themselves, however, are not completely the same in the sense that they take different positions in the hierarchy of values as well as on the PLUS-MINUS axis-which jointly make the Domain of Values.

As underlined at the outset, both films are connected by the relationship of remaking. This factor alone results in many of the values from the original film being present in its remake. The fact that the Cowboy and the Samurai act alike on the basis of their culture also contributes to the number of similarities the two archetypes share.

The protagonists share many of the values that appear most often in filmsthe vital values stemming from bravery and readiness to face danger. However, whereas the Samurai is willing to confront even extreme odds and give his life if required, the Cowboy follows a more cautious approach. This is illustrated throughout the movies where the Samurai fights significantly more enemies at once and, during the last scene, confronts the antagonist with all his allies at once- the Cowboy, on the other hand, duels just the antagonist and after disarming him proceeds 
to fight the rest of his gang. Another difference in vital values is the Samurai's frugality and the Cowboy's penchant for drinking and smoking, as well as earning money. This is transparent in one of the first scenes where, in both films, the main character enters the restaurant or the inn. In Yojimbo (1961) Sanjuro orders a mere bowl of rice but in A Fistful of Dollars (1964) Joe wants alcohol. Contrast between the two archetypes is also noticeable on the second level of the value system - the Samurai's actions are more often guided by the strict adherence to his code of conduct. Even though the moral values of both characters are comparable, they are less visible in the Cowboy's actions, who seems to be driven by the desire to earn money and try his own strength than to enact justice and help others. In the end however, he acts similarly to his Samurai counterpart by bringing justice, staying true to his friends and willingly offering his money to allow a persecuted family to escape.

Value system of the Cowboy:

1. bravery, readiness to face danger, partiality to drinking and smoking, earning money-"vital" values

2. expertise in combat, perception, quickness, intelligence- - "cognitive" values

3. patience, charm, optimism, humour- "emotional" values

4. loyalty, justice, honour, willingness to help the weak - "moral" values

5. courtesy, actions and clothes related to one's culture- "customary" values

6. maintenance of one's own equipment and clothes - "aesthetic" values.

The proposed systems of values of the Samurai and the Cowboy are based on their frequency of occurrence in the film, which defines their importance. ${ }^{4}$

Values system of the Samurai:

1. bravery, readiness to face danger, willingness to die, frugality — "vital" values

2. benevolence, loyalty, justice, honour, duty - "moral" values

3. expertise in combat, perception, quickness, intelligence - "cognitive" values

4. courtesy, actions and clothes related to one's culture- "customary" values

5. patience, stoicism, calmness - "emotional" values

6. maintenance of one's own equipment and clothes - "aesthetic" values.

The conclusion following from the comparison of the above systems of values is that all of the values are shared in both filmic texts but what is essential is their distinct hierarchies, presenting different values on each level of the hierarchy as well as culture-determined exponents of values described in the next section.

In spite of existing during different time periods, both the Samurai and the Cowboy shared many values, some of which may be considered universal. They include cognitive values such as expertise in combat, perception, quickness, intelligence, moral values such as loyalty, justice and honour, aesthetic values, vital values such

${ }^{4}$ Many values present in the film Yojimbo (1961) also appear in A Fistful of Dollars (1964). The reason for this is the relationship of remaking connecting the movies as well as the fact that both cultures are similar in certain aspects, as underlined in the analysis. 
as bravery and courage and emotional values such as patience. No values beyond the set of values adopted from Puzynina and Krzeszowski have been distinguished when comparing both films for their hierarchies of values. The main reasons for that are (i) the fact that the movies are connected by remaking as well as (ii) the overall archetype of the character as presented in the literature. The following examples from the analyzed films illustrate and elaborate on the similarities between the two archetypes - the Samurai and the Cowboy.

\subsection{The encoding of selected shared Cowboy and Samurai values} in the chosen narrative-compositional segments

In the present study we have defined the notion of shared value, the examples of which are shown in this section, with respect to (i) the Domain of Values and (ii) the image evoked by a compositional segment (i.e. film modalities), which reveals their culture specificity.

As regards the Domain of Values, the values shared by both cultures appear on the axes in the described configurations:

1. the same position of the value in the axiological hierarchy and the same position on the PLUS-MINUS scale (axiological charge),

2. the same position of the value in the axiological hierarchy but a different position on the PLUS-MINUS scale (axiological charge),

3. different position of the value in the axiological hierarchy but the same position on the PLUS-MINUS scale (axiological charge),

4. different position of the value in the axiological hierarchy and a different position on the PLUS-MINUS scale (axiological charge).

The moving image of the compositional segment is the key element of the analysis and is defined in relation to the shared scene as well as the culture specific image. For the sake of illustration of the visual exponents of values, only four examples have been offered.

Example 1-vital values (courage) - the same position in the hierarchy and on the PLUS-MINUS scale of the Domain of Values.

Upon entering town where the plots take place, which happens in the PROLOGUE of the compositional-narrative structure, the main characters see a symbol of danger but do not turn back. These symbols are presented differently in the films, which brings back the issue of multimodal translation, as $A$ Fistful of Dollars (1964) is the remake of Yojimbo (1961). The dog carrying a human hand is translated into a dead rider with a sign reading "adios amigo" on his back.

The translation from dog carrying a dead hand to the dead rider reflects the cultural marking of the same value of Japanese and American cultures and at the same time retains its original axiological charge. Despite the different presentation, namely that the hand must have been cut off and the rider shot with a firearm, both scenes are instances of the main character showing courage. 

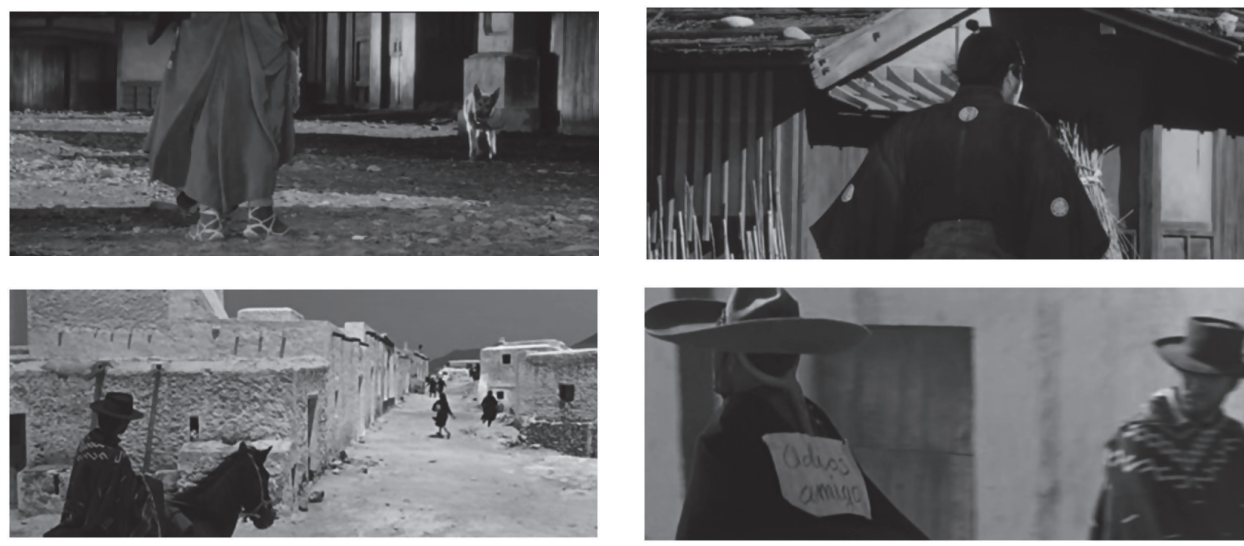

Figure 1: Example of vital values in the movies

Source: A. Kurosawa (Director). 1961. Yojimbo. Japan: Kurosawa Production Co., Toho Company; S. Leone (Director). 1964. A Fistful of Dollars. Italy: Jolly Film S.R.L.

In the situations pictured by the compositional segments, the protagonists of both movies often show courage and bravery, even in face of danger. Therefore, this segments resemble the following configuration: 1. the same position of the value in the axiological hierarchy and the same position on the PLUS-MINUS scale (axiological charge).

Patterns of Krzeszowski's (Angels) FAMA explain the axiology of these scenes as they allow for the charge values to be distinguished. In both movies the symbol of danger (negative charge) is moving towards $(\rightarrow)$ the protagonist (positive charge), which evokes the second schema of FAMA with the final axiological charge being negative. The protagonist demonstrates his courage and is unmoved by the approaching danger. After that, the symbol of danger (negative charge) moves away $(\longleftarrow)$ from the protagonist (positive charge), who continues his way into the town. This evokes the sixth schema of FAMA, where the final axiological charge is positive. Thus, the scene ends in an Axiological Balance.

Example 2-moral values (loyalty) - different position in the hierarchy and the same position on the PLUS-MINUS scale of the Domain of Values.

Protagonists in both films remain loyal to those who have given them shelter and became their friends, as shown in the DENOUEMENT phase of the compositional-narrative structure. In Yojimbo (1961), the main character, after learning what happened to his friend - the restaurant owner Gonji-rushes immediately to his help. In A Fistful of Dollars (1964), the drifter Joe does the same, wanting to rescue Silvanito, the tavern keeper.

These scenes are very similar in the analyzed films as both protagonists are moved by their friends' abduction and immediately rush to their rescue. This shows their dedication and loyalty and contributes to moral value in the axiological hierarchy. The scenes evoke the following configuration: 3 . different position of the 

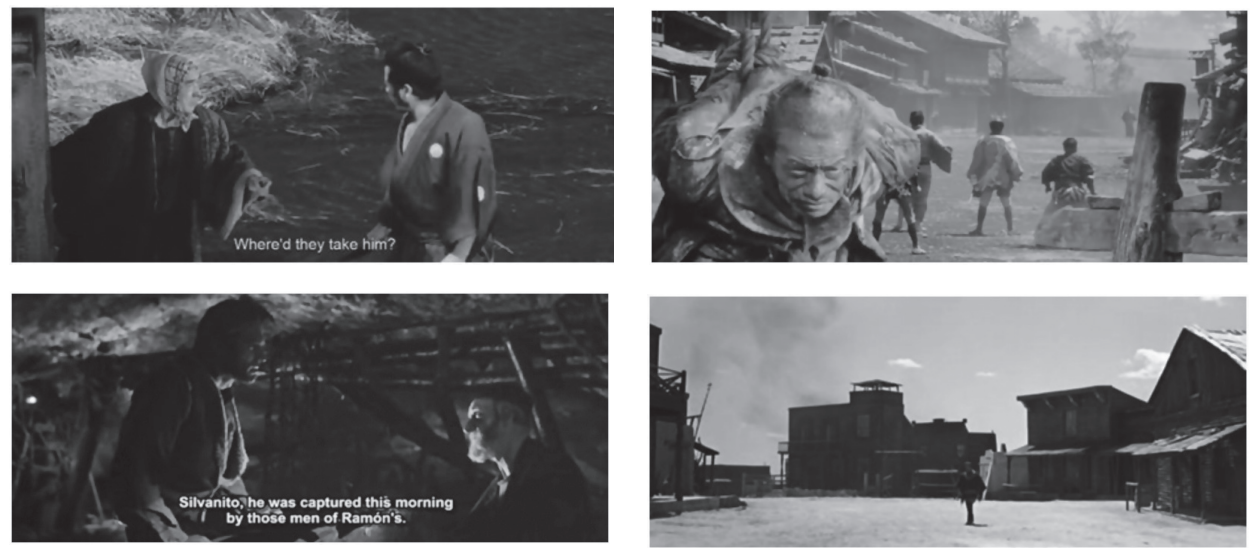

Figure 2: Example of moral values in the movies

Source: A. Kurosawa (Director). 1961. Yojimbo. Japan: Kurosawa Production Co., Toho Company; S. Leone (Director). 1964. A Fistful of Dollars. Italy: Jolly Film S.R.L.

value in the axiological hierarchy but the same position on the PLUS-MINUS scale (axiological charge).

The main characters go to the town to free their friend (positive charge) who has been captured $(\rightarrow)$ by one of the gangs (negative charge). This correlates with the third schema of FAMA where the final axiological charge is negative. The protagonists then confront the gangs and rescue their friends (positive charge) from $(\leftarrow)$ their abductors (negative charge). This situation conjures up the seventh scheme of FAMA with the final axiological charge being positive. The Axiological Clash initiated by the abduction of the protagonists' friends is thus resolved and the Axiological Balance occurs.

Example 3 - vital values (frugality) - the same position in the hierarchy and different position on the PLUS-MINUS scale of the Domain of Values.

One difference between the characters is reflected in the PROLOGUE phase of the compositional-narrative structure. Unlike his Samurai counterpart in Yojimbo (1961), the drifter Joe does not shy away from drinking and socializing with the bandits, even for the sake of keeping up appearances and to forward his plan. When entering Silvanito's tavern for the first time, Joe does not want to drink water but something stronger. Sanjuro, on the other hand, refuses to drink sake when meeting Gonji for the first time, deciding that a bowl of rice is enough for him - this is an example of the Samurai frugality mentioned before.

Values implied by these scenes are positioned differently on the PLUS-MINUS scale of the Domain of Values, as shown in the following configuration: 2. the same position of the value in the axiological hierarchy but a different position on the PLUS-MINUS scale (axiological charge).

In Yojimbo (1961), the main character (positive charge) declines the offer to drink sake and asks the restaurant owner $(\rightarrow)$ to give him rice (positive charge). This situation is connected to the first scheme of FAMA where the final axiological 

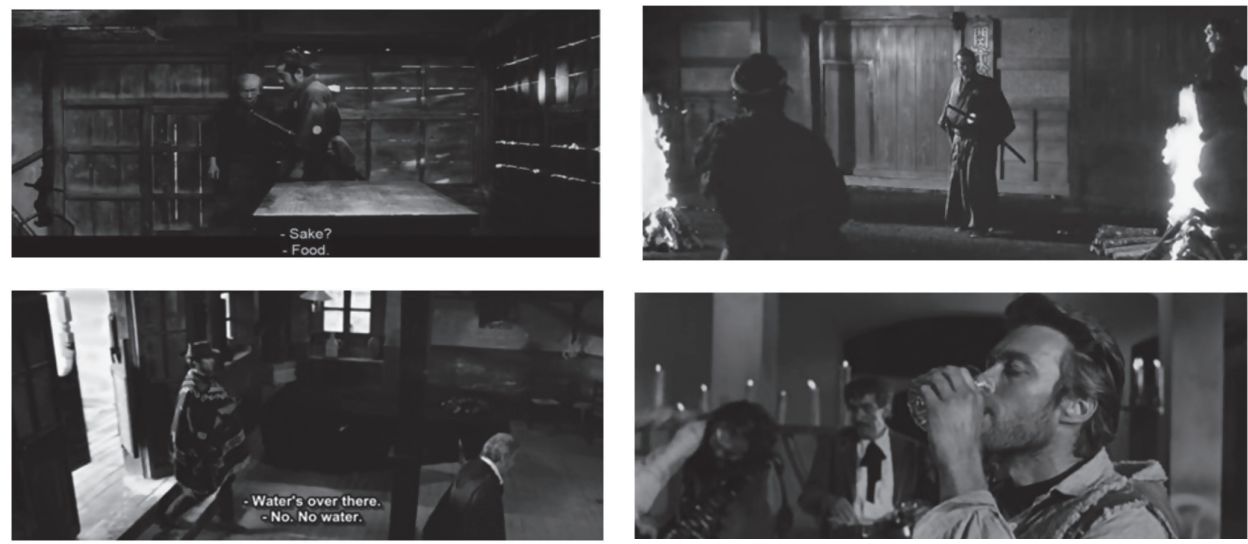

Figure 3: Example of vital values in the movies

Source: A. Kurosawa (Director). 1961. Yojimbo. Japan: Kurosawa Production Co., Toho Company; S. Leone (Director). 1964. A Fistful of Dollars. Italy: Jolly Film S.R.L.

charge is positive. In A Fistful of Dollars (1964), on the other hand, the protagonist (positive charge) does not want to be given $(\rightarrow)$ water and asks for something stronger (negative charge) instead. The above scene evokes the third schema of FAMA where the final axiological charge is negative. The result is that values are placed on a different side of the PLUS-MINUS scale of the Domain of Values.

Example 4-customary values (clothing and weapons) - different position in the hierarchy and different position on the PLUS-MINUS scale of the Domain of Values.

Culture and customary values make for the most conspicuous differences between the analyzed movies. There are many examples of such distinctions. Clothing and weapons the main character uses are the most obvious ones as they are visible throughout the whole film. In Yojimbo (1961), Sanjuro wears a robe and carries a katana, whereas Joe in A Fistful of Dollars (1964) wears his distinctive poncho and carries a revolver. This is also true for the antagonists, whose weapon differs from that carried by the rest of the movie characters. In Yojimbo (1961) the antagonist, Unosuke, carries a firearm where everyone else wields a katana and in A Fistful of Dollars (1964) the bandit Ramon is famous for his skills with a rifle and is the only person who uses it in the film.

The differences that impact the Domain of Values occur in the DENOUEMENT phase of the compositional-narrative structure, in the scene of final confrontation - the showdown. There, the antagonist of Yojimbo (1961) uses a revolver - a weapon that was not in common use in Japan at the time. He does not duel with the main character one on one, choosing instead to engage with his firearm, accompanied by his gang. Sanjuro is using his katana (positive charge) to engage $(\rightarrow)$ Unosuke carrying his revolver (negative charge). This resembles the third scheme of FAMA where the final axiological charge is negative. In A Fistful of Dollars 

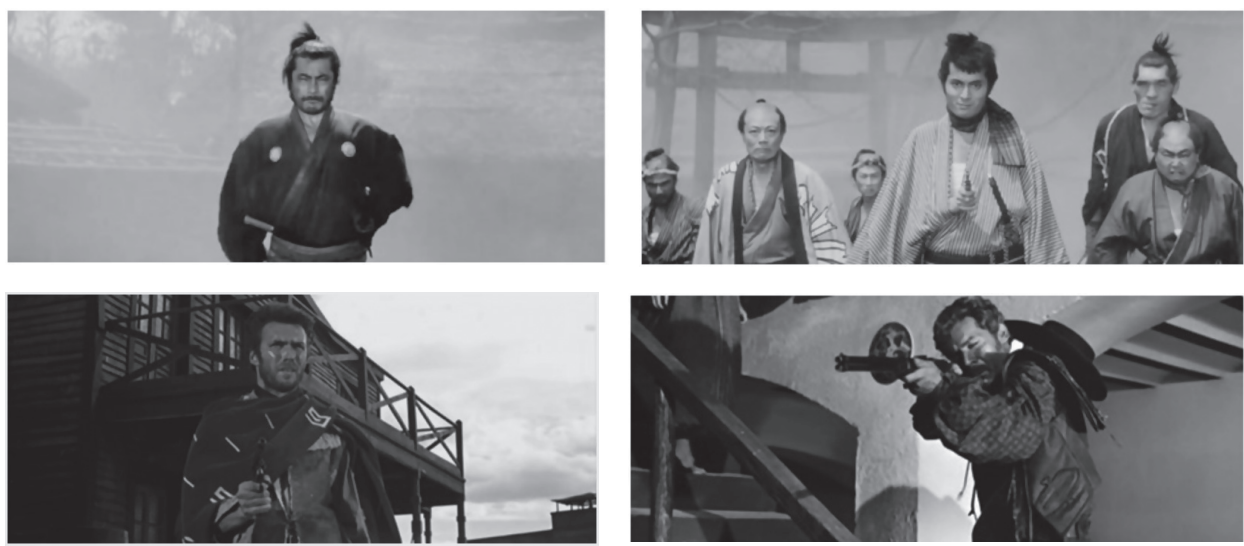

Figure 4: Example of customary values in the movies

Source: A. Kurosawa (Director). 1961. Yojimbo. Japan: Kurosawa Production Co., Toho Company; S. Leone (Director). 1964. A Fistful of Dollars. Italy: Jolly Film S.R.L.

(1964), the protagonist and the antagonist both use firearms common to the Western culture when battling one another-Joe is using his revolver (positive charge) and $(\rightarrow)$ Ramon fights using rifle (positive charge). They also do it one on one, with Ramon's gang being already defeated by Joe. This situation evokes the first scheme of FAMA, the final axiological charge being positive.

Apart from the different position on the PLUS-MINUS scale of the Domain of Values, these values also differ in their location in the hierarchy of values, as shown by the configuration: 4 . different position of the value in the axiological hierarchy and a different position on the PLUS-MINUS scale (axiological charge).

\section{Conclusion}

Our general interest in this paper was in the axiological elements of the chosen filmic texts connected by remaking. The complexity and length of these texts as well as their multimodality make the examination of their axiological elements a real challenge. Thus, the specific aim of the paper was to outline a possible methodology for the axiological analysis of filmic texts to and to present the example analysis supporting it.

The axiological analysis described in this paper relies on the theories by Krzeszowski (Angels, Aspekty, Meaning, Translation), Puzynina ("Językoznawstwo", $J e ̨ z k$ ) and Post (Speech) all concerning the axiology of language and its instruments. With their theoretical and descriptive proposals it was possible to distinguish the values and axiological charges of chosen filmic segments and to underline the differences and similarities between values and axiological charges present in both movies. The aforementioned were achieved by conducting a multimodal 
analysis of selected movies' fragments and discerning the place of values simultaneously in the hierarchy of values and on the PLUS-MINUS scale of the Domain of Values. Within the proposed framework it was possible to establish that the cultural values present in the two films are universal types of values that are largely the same, hence the related concept of shared value which allows for the difference of their places in the hierarchy of values and the PLUS-MINUS scale in the Domain of Values. Adding axiological charges and values as a complement to the overall meaning created by the three filmic modalities makes it possible to obtain the complete meaning of each filmic segment and, in the end, the complete meaning of the entire film.

Hopefully, the presented interpretive model and the analysis based on it show that the aforementioned instruments work jointly and successfully in establishing axiological charges of filmic segments and of the location of values they imply in the hierarchy of values. This encourages further research on axiological aspects of not only filmic texts but also of multimodal texts in general. In the first place the scope of axiological analysis of multimodal texts should include the examination and description of modes as instruments of valuations and of the axiological structures of such texts. The final conclusion to this paper is that in order for the analyses of multimodal texts to be complete, axiological considerations should be incorporated into them.

\section{References}

Barsam, R. M., and D. Monahan. 2010. Looking at Movies: An Introduction to Film. New York: W.W. Norton and Company.

Bateman, J. A. 2014. Text and Image: A Critical Introduction to the Visual/Verbal Divide. New York: Routledge.

Bateman, J. A., and K.-H. Schmidt. 2012. Multimodal Film Analysis: How Films Mean. New York: Routledge.

Burn, A. 2013. The Kineikonic Mode: Towards a Multimodal Approach to Moving Image Media. NCRM Working Paper. London: NCRM.

Cleary, T., and O. Ratti. 1999. Code of the Samurai: A Modern Translation of the Bushido Shoshinshu of Taira Shigesuke. Boston: Tuttle Publishing.

Freytag, G. 1900. Freytag's Technique of the Drama: An Exposition of Dramatic Composition and Art. An Authorized Translation from the 6th German Ed. by Elias J. MacEwan. Chicago: Scott, Foresman and Company.

Gulino, P. 2004. Screenwriting: The Sequence Approach. London: Bloomsbury Academic.

Knapp, A. M. 1896. Feudal and Modern Japan. Boston: J. Knight Company.

Krajka, W., and A. Zgorzelski. 1974. O analizie tekstu literackiego. Lublin: Wydawnictwo UMCS.

Krzeszowski, T. P. 1997. Angels and Devils in Hell: Elements of Axiology in Semantics. Warszawa:

Energeia.

—. 1999. Aksjologiczne aspekty semantyki językowej. Toruń: Uniwersytet Mikołaja Kopernika.

- 2012. Meaning and Translation. Part 1: Meaning. Frankfurt am Main: Peter Lang. 
-. 2016. The Translation Equivalence Delusion: Meaning and Translation. Frankfurt am Main: Peter Lang.

Lafcadio, H. 1894. Glimpses of Unfamiliar Japan. London: Kegan Paul, Trench, Trübner and Company Limited.

Moskowitz, J. 2006. "The Cultural Myth of the Cowboy, or, How the West Was Won." Americana: The Journal of American Popular Culture (1900-present) 5.1. Retrieved from http://www. americanpopularculture.com/journal/articles/spring_2006/moskowitz.htm. 19 Nov. 2018.

Nitobe, I. 2009. Bushido: The Soul of Japan. Auckland: The Floating Press.

Ostaszewska, D., and R. Cudak. 2008. Polska genologia lingwistyczna. Warszawa: Wydawnictwo Naukowe PWN.

Owen, J. P. 2004. Cowboy Ethics. Ketchum, ID: Stoecklein Publishing.

-. 2008. Cowboy Values: Recapturing What America Once Stood For. Guilford: Lyons Press.

Post, M. 2013. Speech Acts and Speech Genres: An Axiological Linguistics Perspective. Wrocław: Wydawnictwo Wyższej Szkoły Filologicznej we Wrocławiu.

—. 2017. Film jako tekst multimodalny. Założenia i narzędzia jego analizy. Wrocław: Wydawnictwo Wyższej Szkoły Filologicznej we Wrocławiu.

Puzynina, J. 1982. “Językoznawstwo a aksjologia.” Biuletyn Polskiego Towarzystwa Językoznawczego 39. 23-32.

-. 1992. Język wartości. Warszawa: Wydawnictwo Naukowe PWN.

Swales, J. 1990. Genre Analysis: English in Academic and Research Settings. Cambridge: Cambridge UP.

Wildfeuer, J. 2014. Film Discourse Interpretation: Towards a New Paradigm for Multimodal Film Analysis. London: Routledge.

Wildfeuer, J., and J. A. Bateman. 2016. Film Text Analysis: New Perspectives on the Analysis of Filmic Meaning. New York: Routledge. 